\title{
Developing Orientation Leader Training Using Appreciative Inquiry
}

\author{
Sylvester Gaskin and Maia Williams
}

In an attempt to revamp the orientation leader training process, Towson University began using appreciative inquiry (AI) with student leaders to both plan and conduct skilldevelopment workshops. Originally crafted as an organizational development tool, AI served as a powerful way to use the collective wisdom of student leaders and built upon their desires for a more impactful training cycle to create a learning environment that was responsive to new leaders' needs and provided the skills needed to support new students coming to the university.

In preparing for summer orientation programming, the training and continual development of student orientation staff takes incredible planning and foresight to ensure student leaders have the skills to do their jobs effectively. After the summer 2014 training cycle, the Office of New Student Programs (NSP) at Towson University began investigating how to modify this process. Through conversations with student staff and professional employees, one question kept coming up: How can we do training better? From our summative assessment of training, students felt they had the tools to work with first-year students, but new staff wanted to hear more from returning student leaders. In turn, returning student staff wanted to share their knowledge with their peers. The idea to employ appreciative inquiry for the planning of the 2015 training process came from this realization.

\section{Introduction to Appreciative Inquiry}

Appreciative inquiry (AI) was created by David Cooperrider and his graduate school adviser, Suresh Srivastva, at Case Western Reserve University in Cleveland, OH (Lehner \& Hight, 2006). While looking at organizational development models, Cooperrider noticed that deficit-based approaches to solving problems were common. Instead of looking at what doesn't work in an organization, Cooperrider and Srivastva decided to tackle major issues by looking at positive areas of a group that were functioning at high levels. Examining processes through a lens of positivity and potentiality gives participants energy to think about how they can use their strengths and ideas to improve organizations. Appreciative inquiry has been used in a variety of arenas within higher education (Cockell \& McArthur-

Sylvester Gaskin (sgaskin@towson.edu) is the Assistant Director of New Student Programs at Towson University

Maia Williams is Student Director for Assessment at Towson University 
Blair, 2012), including diversity education (Alston-Mills, 2011; Gaskin \& Gilgoff, 2013), reorganizing student affairs units (Fifolt \& Stowe, 2011), and service learning experiences (Lahman, 2012; Mather \& Konkle, 2013). Appreciative inquiry has also been employed in academic department reorganization (Giles \& Yates, 2011), curriculum development (Fergy, Marks-Maran, Ooms, Shapcott, \& Burke, 2011), working with at-risk students (Martin \& Calabrese, 2011), and with online learning (Johnson, 2014).

The AI model is based off of five key principles: People create their own reality based upon their experiences, questioning and changing organizations happens together, sharing stories about the organization helps improve it, thinking positively about the future helps shape the desired change, and people within organizations are naturally directed toward positive energy (Lehner \& Hight, 2006). Appreciative inquiry gathers people in a working team and has them use a "4-D" cycle to promote positive change. The first step, discover, has participants thinking about aspects of the organization that work particularly well. The second step, dream, involves participants imagining how their ideal working environment would function. The third step, design, gets participants working on crafting the perfect organization and creating strategies that will enable success. The last step, destiny, is the actual implementation of those strategies (Elleven, 2007).

\section{The AI Process at Towson University}

Our journey with AI began after orientation in September 2014. There was growing concern that NSP was not using the collective wisdom of returning student staff to train new leaders. Professional staff also wanted to ensure that the OL role matched student employees' expectations for leadership development and building community (Gansemer-Topf \& Economos, 2012). Staff at NSP researched qualitative survey methods that utilized AI concepts to discover the positive aspects of OL training and the potential for expanding on them. It was critical to keep the assessment short and focused on positive questioning (Conkright, 2011). We wanted to get a better idea of what kept students positive despite working in difficult situations.

Our September assessment asked a series of AI-focused questions. We asked "What gave you energy throughout the training process," "Tell us a time when you felt deeply engaged about a discussion or topic during training," "Which skits/ presentations made you feel most prepared to do your job," and "Imagine it is time for summer 2015 training; what do you feel you could present that energized your colleagues and get them ready for orientation?" The use of terms like "energy," "imagine," and "engaged" were important; focusing questions on staying positive and futuristic helps participants focus their thoughts on how they could build a better experience (Tiem \& Rosenweig, 2008). Results from this survey showed that OLs enjoyed spending time with their more senior student leaders, having their peers provide presentations rather than professional staff, and OLs discussing amongst themselves diversity and social justice issues.

With this information in mind, NSP staff went about selecting orientation 
team leaders (OTL) to serve as trainers for the 2015 orientation season. Once the staff was hired, the Student Director for Assessment (SDA) started an appreciative inquiry 4-D process with the OTL cohort, using the previously mentioned assessment results as a starting guide. Since this group of students was charged with training new staff, NSP focused its questioning on creating a positive training curriculum. The discovery process began in February 2015 during planning meetings. New OTLs were asked, "When were you at your best during your training experience?" and "What kept you engaged through the process?" The discovery phase is one of inquiry and of mutual learning, so it was important for the SDA to guide OTLs toward telling stories of exciting times during training (Watkins, Mohr, \& Kelly, 2011). This discovery phase took the better part of two planning sessions; OTLs had to really think about all their varied experiences and focus on what was the most positive. OTL staff responded that positive moments of their training included learning from returning student staff, participating in icebreakers, and realizing they were in a position to positively impact a new student's experience on campus.

The second phase of the AI process, dream, took place over two planning meetings in February and March of 2015. The SDA asked a simple question: "What would the most impactful orientation training look like?" From this, OTLs collectively shared their ideas from the discovery phase and from the previous summer's assessment to start drafting a template schedule. The dream phase was a critical moment in the planning process; OTLs wanted to solely schedule the training, but the SDA challenged leaders to plan with the intent of creating an environment in which all staff felt valued (Cooperrider \& Whitney, 2005). Student leaders all agreed that peer-to-peer training was critical in crafting a dynamic learning environment, small group discussions allowed newer staff to ask questions in a more intimate setting, and vignettes in which staff could practice their new skills were important. The template schedule also had icebreakers built in to energize OLs in between sessions and even ending training between 4-5pm each day to give staff time to rest and have dinner with friends.

The third phase, design, took place in April 2015. Each OTL was tasked to lead a training seminar on specific topics staff members needed to learn in order to be successful. The SDA created learning templates to guide OTLs in their lesson plan development. Focusing on the desire of student staff members to learn from their peers, this process encouraged the OTLs to work together to share best practices amongst each other, so that they could relay the information to orientation leaders. Topics included handling difficult conversation topics, using StrengthsQuest results to better understand how teams can work effectively, and locating campus resources that incoming students needed to know about. In this phase, the desire to have the majority of OL training led by peers manifested. A final design meeting took place in August before OL training began in earnest.

The final phase, destiny, took place during August OL training. As training got underway, both new and returning staff commented to the SDA about the high levels of energy present during training and the excitement of having returning staff train new OLs on topics discussed through the AI process. A summative assessment 
was sent to the entire student staff after the August orientation had concluded, and results showed that OLs valued the peer-to-peer training methodology and found the conversation time with other student staff valuable in team building. Student leaders commented on their high level of preparedness to work with firstyear students and felt a deeper connection with OTLs who were responsible for providing guidance to OLs during orientation. The survey showed that using AI yielded the desired effects and can be used as a building block for future training. With these results, the AI process will begin once student staff members are selected for the 2016 orientation cycle to ensure continued successes.

\section{Conclusion}

Our experiment with appreciative inquiry showed us that creating a positive leader training environment was possible through using the 4-D process. Through intentional planning and focus on positivity, student staff can have a major impact on delivering material that all orientation leaders will need. In addition, the AI process delivered on building a cohesive team in which positivity is created through dreaming of the future and deeper interactions amongst student leaders. Appreciative inquiry has been a valuable tool for NSP and will be implemented for future student leader training sessions.

\section{References}

Alston-Mills, B. (2011). Using appreciative inquiry to promote diversity in higher education. Journal of Diversity Management, 6(3), 1-5.

Cockell, J., \& McArthur-Blair, J. (2012). Appreciative inquiry in higher education: A transformative force. San Francisco, CA: Jossey-Bass.

Conkright, T. A. (2011). Improving performance and organization value through a virtual appreciative inquiry summit. Performance Improvement, 50(6), 31-37.

Cooperrider, D., \& Whitney, D. (2005). Appreciative inquiry: A positive revolution in change. San Francisco, CA: Berrett-Koehler

Elleven, R. K. (2007). Appreciative inquiry: A model for organizational development and performance improvement in student affairs. Education, 127(4), 451-455.

Fergy, S., Marks-Maran, D., Ooms, A., Shapcott, J., \& Burke, L. (2011). Promoting social and academic integration into higher education by first year student nurses: The APPL project. Journal of Further and Higher Educaion, 35(1), 107130.

Fifolt, M., \& Stowe, A. M. (2011). Playing to your strengths: Appreciative inquiry in the visioning process. College and University, 87(1), 37-40.

Gansemer-Topf, A., \& Economos, K. (2012). "I don't just give tours": Examining what students learn from the student orientation leader experience. The Journal of College Orientation and Transition, 20(1), 19-30.

Gaskin, S., \& Gilgoff, J. (2013). Safety-support-skills-success: The road to 
scholarship for college men of color. The Changing Faces of College Men.

Retrieved from http://www.naspa.org/kc/mmkc/Joint\%20Publication\%202013. pdf.

Giles, D., \& Yates, R. (2011). Re-culturing a university department: A case study. Management in Education, 25(3), 87-92.

Johnson, B. A. (2014). Transformation of online teaching practices through implementation of appreciative inquiry. Online Learning, 10(3), 1-21.

Lahman, M. (2012). Appreciative inquiry: Guided reflection to generate change in service-learning courses. Communication Teacher, 26(1), 1-5.

Lehner, R., \& Hight, D. L. (2006). Appreciative inquiry and student affairs: A positive approach to change. College Student Affairs Journal, 25(2), 141-151.

Martin, T. L. S., \& Calabrese, R. (2011). Empowering at-risk students through appreciative inquiry. International Journal of Education Management, 25(2), 110123.

Mather, P. C., \& Konkle, E. (2013). Promoting social justice through appreciative community service. New Directions for Student Services, 143, 77-88.

Tiem, D. V., \& Rosenweig, J. (2008). How are we doing? "Best of ISPI" appreciative inquiry member survey. Performance Improvement, 47(7), 5-11.

Watkins, J. M., Mohr, B., \& Kelly, R. (2011). Appreciative inquiry: Change at the speed of imagination (Vol. 2). San Francisco, CA: Wiley.

\section{Appendix 1: AI Visioning Questions}

1. What gives you a sense of purpose as an OTL? What gives the same sense of purpose as a trainer?

2. What do you hope future orientation leaders get from their training?

3. When are we at our best during training and how can we get there more often?

4. What makes a training session engaging for you?

5. What should people look forward to most after training?

6 . What is the main factor that gives life to orientation training?

\section{Appendix 2: AI Summative Survey Questions}

1. Tell us about a time when you felt deeply engaged about a discussion or topic covered during your days of training. When during training did you feel this high level of engagement and what topic/item was being discussed?

2. Your training period involved presentations presented by OTLs and outside faculty/staff that were designed to help prepare you for your job. Which of these skits/presentations were the most impactful and helped you in your job?

3. What do you hope is covered during training as staff prepare for the 2016 orientation season?

4. Imagine you have been asked to cover a topic during 2016 orientation leader training. What topics would you want to share your knowledge and expertise on and why? 